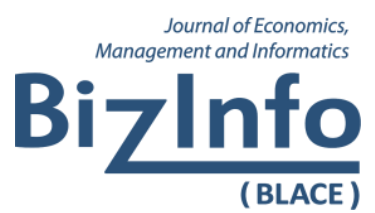

Year 2019, Volume 10, Number 2, pp. 111-123

\author{
Прегледни рад/ Review paper \\ УДК/UDC: 005.953:005.841]:004.738.5 \\ doi:10.5937/bizinfo1902111S
}

\title{
CONDUCTING PRE-EMPLOYMENT BACKGROUND CHECKS THROUGH SOCIAL NETWORKING SITES: THE NEW ROLE OF HR PROFESSIONALS
}

\author{
Md Sajjad Hosain ${ }^{1}$ \\ Sichuan University, Business School, Chengdu, China \\ Ping Liu \\ Sichuan University, Business School, Chengdu, China
}

\begin{abstract}
The paper aims at identifying the role of social networking information on pre-employment background check practices with the help of existing literature. As the HR professionals are central in hiring process, they need to be aware of the practices and policies regarding this issue. Using social media information in background checking process is a fairly new practice and there is not enough evidence on what to do and how to do. This paper is expected to fill that gap to some extent. At the end of the paper, some policy recommendations have been provided for HR professionals involved with pre-employment background checking process which will help the recruiters or HR professionals to avoid any unexpected consequences.
\end{abstract}

Keywords: Social media, Social networking sites, Information, HR professionals, Pre-employment background check, Job candidate.

\section{INTRODUCTION}

In the year 2017, it was found that $81 \%$ of the US population has a social media profile (Statista, 2017). According to the survey conducted by Statista, (2017), Facebook has the highest number of users having 1.86 billion accounts. The other social networking sites (SNSs) also have a good number of user profiles around the globe. Such profile holders are intentionally or

${ }^{1}$ sajjad_hosain@yahoo.com 
intentionally providing huge information that can be accessed by the friends or even by the public (if the profile is public). The information available at SNSs are now attracting the employers increasingly to search and evaluate prospective employers' background and organizational fit (Berkelaar \& Buzzanell, 2014). In recent times, employers are increasingly interested in utilizing social networking sites such as Facebook, LinkedIn and Twitter in order to screen job applicants (Weathington \& Bechtel, 2012). While people are exposing themselves via SNSs, employers seek to understand more regarding job applicants (Jobvite, 2014). It was evident that applicants' online activities like comments, posting and sharing can increase their appeal to the employers raising the chances of employability scale (Harrison \& Budworth, 2015).

There are more than hundreds of social networking sites available with a differentiated range of interests and practices (Suder, 2014) help to connect people, comment and sharing the views regarding personal, professional and even political views (Boyd \& Ellison, 2007). Employers are increasingly using SNSs as the tools for screening job applicants (Elzweig \& Peeples, 2009; Waring \& Buchanan, 2010; Brown \& Vaughn, 2011; Slovensky \& Ross, 2012; Messiah, 2012). The reasons for utilizing SNSs in recruiting and screening are multifaceted and include a wide variety of employers' intentions. Some notable causes are cost saving intentions and easily available information that would not have been possible to collect otherwise or from any other sources. Employers have successfully reduced the cost of recruitment and screening down to half using SNSs (Cooley \& Parks-Yancy, 2016). In addition, 65\% employers evaluated the character and integrity of applicants based on the information available at social media profiles (Messiah, 2012). The other notable reason is that information are easily available at social networking sites that might be used as complementary source of prospective employee lifestyle and representation which thought to be helpful in judging the personality and organization/job fit. For example, applicants' community services or participation in social causes can make them acceptable to the employers that would increase the chance of hiring (Parks-Yancy \& Coolley, 2016).

However, such SNS screening are not free from limitations. In such attempts, employers carry the risk of being accused for violating the privacy and can be legally held accountable. They can be legally responsible for screening candidates based on personal information protected by state and national law (Saylin \& Horrocks, 2013). The next most important issue is ethical consideration of using SNS information for candidate hiring and screening that could substantially reduce the reputation and brand image of the company. 
CONDUCTING PRE-EMPLOYMENT BACKGROUND CHECKS THROUGH SOCIAL NETWORKING SITES: THE NEW ROLE OF HR PROFESSIONALS

Despite of being a considerably important and emerging issue, the area of utilizing SNS information for pre-employment screening lacks research evidence and attention of academia. There are not proper guidelines form research as well as professional perspectives regarding questions like should the firms use SNS information for pre-employment background check? What information should be utilized and what others should be avoided (as some information are job related and some are not), How the information should be processed and screened? What should be the role of HR professionals in this regard? This paper attempts to answer these important questions through existing literature findings. In addition, some action recommendations have been also provided at the end.

\section{LITERATURE REVIEW}

Social media have become one of the mostly utilized procurement and screening tools of employment. With billions of social networking accounts around the globe, employers find a suitable source of job placement (ParksYancy \& Coolley, 2015). Social media have become the avenue of selfpromotion and status building (Tham \& Ahmed, 2011). According to Jobvite, (2014), more than 15\% employers use or planning to utilize social media for recruitment purpose. Both the employers and job applicants are using social media to hire and to be hired. As noted earlier, social media reduced the cost of hiring substantially and gave employers opportunity to evaluate job applicants' information with the help of their SNS profiles. A notable number of reputed organizations have created their organizational profile at Facebook, LinkedIn and other social networking sites to attract talents. On the other hand, job applicants are utilizing social media to manage and increase their online presence to gain positive attention of employers (ParksYancy \& Coolley, 2016). They follow the job advertisement updates posted on the organizational profiles and pages. When the person likes or applies for those specific job posted on SNSs, the employers can easily conduct some information mining through the postings and other activities of that specific applicant. Although, LinkedIn is considered as the only job specific social networking site, in reality, employers try to visit all social networking sites when screening for prospective employees (Brooks, 2016).

\subsection{SNS information in pre-employment background check}

Conventionally, pre-employment background checks include job records investigation from previous employers, criminal records usually conducted by the police reports, financial credit check through independent financial bureaus and civil judgments through the local community or government volunteering job records. More recently, employers can and afford to go beyond the traditional background checks and have the access and 
opportunity to a variety of online and social platforms such as Google profile, Facebook, LinkedIn, Twitter to conduct the same. This part of the paper will discuss the different online social platforms that are available for the employers to conduct pre-employment background checks.

An organization can get and process information regarding job applicants through online search engine such as Google, Yahoo and Bing. The information that show up on these online platforms can be collected, processed and reviewed to get a comprehensive picture about the candidate which assist to take the decisions regarding hiring and screening. With this type of search that can save more than 80 per cent time, the hiring managers are looking for proof that the job seeker is who they he/she is and would be a "good" fit in the organization (Joyce, 2016).

Whilst some employers are simply willing to carry out an online search, very recently, more and more employers are accessing candidates' social media pages as part of the screening process (Zeidner, 2007). Such investigation can be done in numerous ways. As for example, HR managers may request to be 'friended' by the job applicant and this would allow the employers to search the candidate's profile and connections (Segal, 2017). Furthermore, companies may ask current employees who are already connected to the candidates for accessing to the candidates' social media pages (Brandenberg, 2008).

Finally, some employers or hiring authorities are asking candidates directly to give their social media links/IDs and passwords in the interviewing process (Yarbrough, 2018). Recently, both the employers of public and private jobs are increasingly asking the candidates to provide their social media IDs and passwords as part of the interview process (Ramasastry, 2012). Such practices are more evident in western countries than those of Asian and African countries. The logic presented by employers behind such policies and practices are that access to personal accounts is needed to protect proprietary information or trade secrets, to comply with federal financial regulations or to prevent the employer from being exposed to legal liabilities for negligent hiring (National Conference of State Legislatures, 2017). There is a continuous debate in academia and practical arena whether all information are necessary for pre-employment background checks or not. In fact, some information are protected by law and employers can face lawsuit if such privacy issues are compromised in the name of background check. The next part of the paper is going to discuss that issue. 


\subsection{Selection of information for pre-employment background check}

In hiring process, employers use a variety of background screening tools such as CVs, references, no objection letter (NOC), experience letter etc. In recent years, employers are also utilizing online and social platforms to screen applicants. One notable example is investigating applicants' SNS accounts, which some employers are already doing (Baumhart, 2015). It is a wellknown fact that there are two types of information in social media: public (open to all) and protected (only seen by friends on SNSs). If an employer is limited to only the information that an applicant has made publicly available on an SNS, there would be little or no chance for debate as such information have been intended to be seen by everyone even who is not connected to that specific profile holder. An applicant cannot logically expect that information made publicly available will remain protected from anyone, including prospective employers (Baumhart, 2015). But a more insidious practice appears to be emerging, however, requesting access to the applicant's private SNS account information (Gates, 2013). Applicants' SNS accounts often contain information that employers are forbidden from considering when making hiring decisions, such as age, race, and sex. Employers' access to such information could lead to discrimination lawsuits when the applicant is not hired. Requiring that applicants disclose password information will also likely violate the SNS's terms of service (Egan, 2012), exposing both the applicant and the employer to some extent of liability. Because of the nature of SNSs, the information contained within is also highly vulnerable to concerns regarding accuracy and authenticity (Ghoshray, 2013). Furthermore, requesting access to an applicant's private SNS content could foster an environment of distrust and create tension between the applicant and the employer that persists after an employee is hired (Brutocao, 2012). Eventually, in an effort to obtain as much relevant information as possible, employers may request (indeed, some already do) access to the private contents of applicants' SNS accounts. In the absence of legal protections, applicants have few options other than to keep such requests. However, employers should collect the job related information such as previous job records, academic achievements, career progression recognition, rewards received rather than screening private information such as gender, race, ethnicity, marital status, personal relationship status in order to conduct preemployment background checking.

\subsection{Information processing and screening}

In general, pre-employment background check falls under the job duties of hiring professionals who are important parts of an HR department. After building the pool of candidates who best match the job requirements, the 
hiring professionals obtain written permission to perform background check popularly known as pre-employment screening. If the result comes in favor of the candidate, he/she is offered the job. On the other hand, negative results make the candidate out of the consideration. The detail of the background check has been depicted through figure-1:

Figure 1. The typical pre-employment screening process through social media

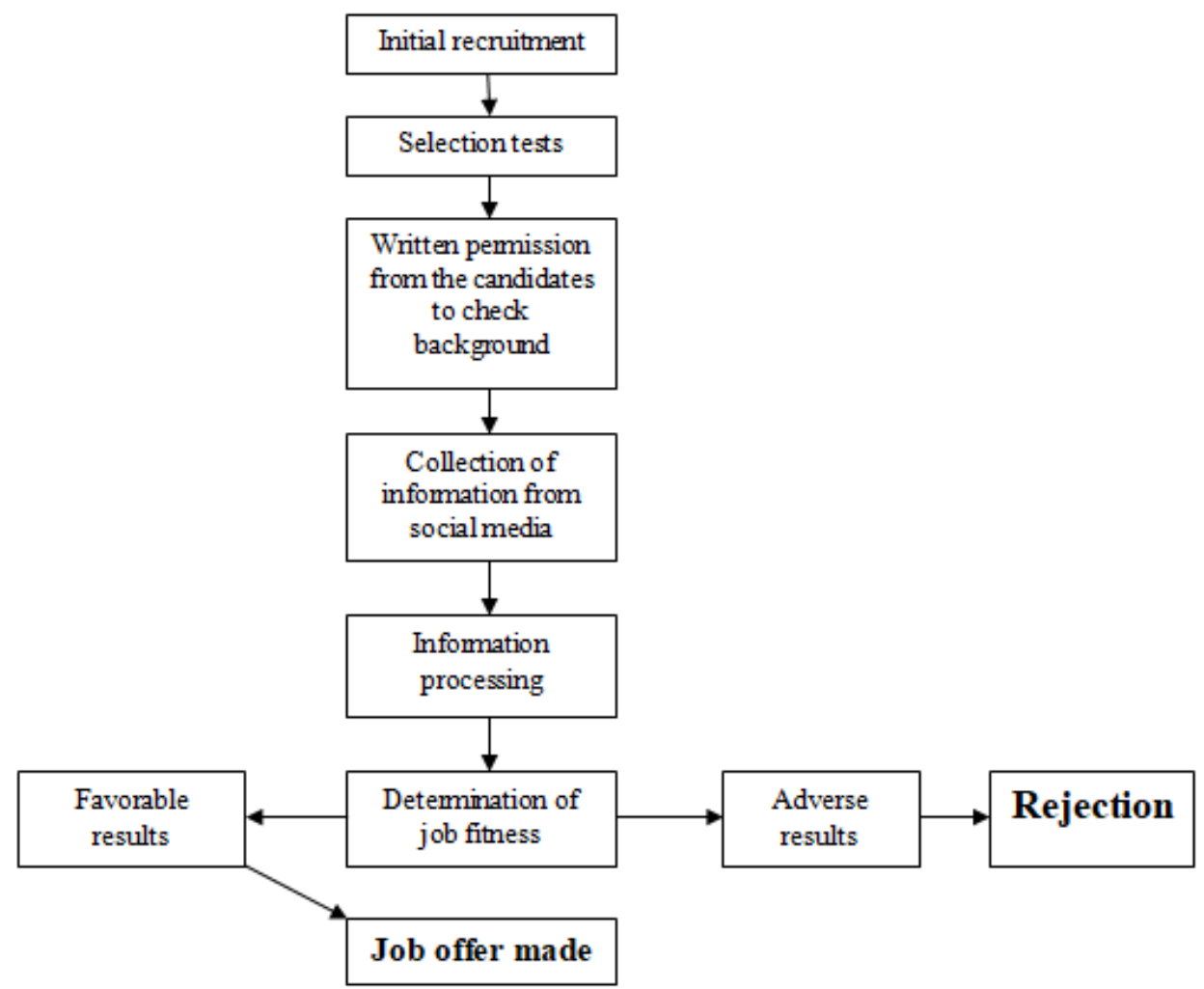

Source: Author elaboration

\section{PRE-EMPLOYMENT BACKGROUND CHECK THROUGH SNSS: POLICY RECOMMENDATIONS FOR HR PROFESSIONALS AS A NEW ROLE}

The IT, legal and HR departments are needed to work as a team in present reality of screening job applicants based on social networking information. HR departments, in particular, need to concentrate more in this recent issue to be clear from all questions and lawsuits as they are central in recruitment \& selection functions. The ever increasing debate of discrimination and privacy will expected to rise in near future as there is no clear and universal policies of how to utilize social networking information in hiring practices. 
The HR departments can make a clear policy of screening candidates based on social media information and that can be informed in detail to the applicants recruited primarily. A clear policy and training for hiring professionals might reduce the chances of discrimination and legal risks to the lowest possible extent. Further, the information gathered should be kept confidential and only be utilized for the screening purpose. Finally, the same procedure should be applied for all candidates irrespective of age, gender, race, religion, ethnicity and geographical locality. This part of the paper highlights some policy recommendations based on previous literature:

- Identification of sensitive information (Stouhghton et al., 2015; Gruzd et al., 2017): The employers and recruiters should identify and aware of the information that are labeled to be sensitive by applicants as the use of such information may reduce the attractiveness of an organization during the different stages of selection process, especially if such practice is known to the applicant pool (Stouhghton et al., 2015).

- Avoidance of social, non-job related information as much as possible (Ollington et al., 2013; Davison et al., 2016; Gruzd et al., 2017): The hiring professionals need to collect as much job related information as possible such as experience, previous job record, skills, presentability, negotiation power etc. for background check. On the other hand, they should avoid social and non-job related information such as friend circle, habits, connections (Ollington et al., 2013) as much as possible which consistently marked as most intrusive information (Gruzd et al., 2017). Some authors (Davison et al., 2016) suggest that employment based social networking sites like LinkedIn would have more workrelated information and be viewed more positively by legal decisionmakers.

- Establishment of a clear social media policy (Willey et al., 2012): Organizations practicing SNS information for background check must have a clear social media policy (SMP) for both the applicants and the hiring professionals. Such precise policy can help in reducing the confusion and over-reliance on personal discrimination tendency.

- Training of hiring professionals (Willey et al., 2012): Mere formulating policy is not adequate. The hiring professionals must be trained on which type of and how to access, collect and utilize social media information in job screening.

- Checking the validity and reliability of information obtained (Davison et al., 2016; Van Iddekinge et al., 2013): Information obtained from social networking sites should be validated and reliability checked to the highest extent possible. There are some third-party consultants (e.g., Social Intelligence) that screen SNSs for various characteristics (and purposes) and provide reports on the job candidates based demographic information collected (Davison et al., 2016). 
- Utilization of SNS information after initial recruitment and before final selection (Gatewood et al., 2008; Segal, 2014; Davison et al., 2016): The social networking screening should be conducted once the candidate is initially recruited and before given final job offer. This would reduce the likeliness of discrimination and legal claim on recruiters.

- Obtaining written permission from candidates (Yarbrough, 2018; Davison et al., 2016): It is imperative for the organizations practicing social media background check to inform, communicate and obtain written permission from the prospective employees regarding social media policy. Such attempts would help to reduce tension for privacy and chance for legal actions from the part of candidates.

- Utilization of social media information as supplementary rather than sole option (Yarbrough, 2018): The SNS information should be used as the supplementary or complementary information for hiring a candidate, not as the sole basis of selection. Even if, any negativity is found in social media account of a job candidate, that candidate should be given a chance to explain it.

- Comparison of assessment results with other predicators (Davison et al., 2016): Employers/hiring professionals should compare the assessment of SNSs with alternative predictors, such as traditional personality tests, background checks etc. This comparison should include both comparisons of validity and adverse impact. Organizations that predictors with higher validity are typically preferred, particularly when they have less adverse impact. The incremental validity of SNS assessments should also be evaluated.

- Establishment of a structured, unified and standardized procedure (Davison et al., 2016): The overall background screening process should be structured, well-clear, unified and standard. The same test should be applied for all candidates in a unified manner. Such standardization has helped the HR professionals for years to generate structured interviews and will likely to mitigate problems for social media assessors as well (Campion et al., 1997).

- If possible, utilization social media should not be made at all (Davison et al., 2016): Last of all, social media is not recommended for background check if there is no necessity or better alternative exists. As so far, the area lacks enough research evidence regarding the validity and adverse impact, the hiring professionals should avoid such SNS information to the highest possible extent. 


\section{THEORETICAL AND PRACTICAL IMPLICATIONS OF THE STUDY}

The primary objective of this paper is to highlight the HR professionals' role on background checking process with the help of existing literature review. This study is expected to add some valuable contributions to the literature regarding job applicants' background checking practices. Due to an acute lack of research evidence in this specific area of HRM, there is a growing need for evidence on how hiring professionals to be guided by. This importance is more urgent as such practice is closely connected to employee perspectives (such as privacy, fairness and ethics) and legal considerations. On the other hand, those hiring professionals might be liable by the organizations themselves if the question of negligent hiring arises later. Therefore, the hiring professionals are prone to risk from both sides: applicants and organizations. The authors hope that this effort of investigation will contribute both from theoretical and practical perspectives and inspire to conduct more research in upcoming future.

This study will hopefully provide valuable contribution to the literature regarding background screening practices. However, it has a few limitations as well. The paper is based on only on existing literature with no quantitative background. A further study with a larger sample size would allow a broader view of the various types of organizations, as well as, other levels of individuals that participate in the pre-selection background checking process. Further studies could investigate how companies can increasingly formulate and include more guidelines concerning the appropriate manner to utilize the social media in such process (e.g. which information can be included or excluded; what should be considered in a quality pre-employment screening; which information should not be used to protect the company from lawsuits). Another future study could include the perspective of employees' and their views.

\section{CONCLUSION}

So far, the relationship between SNS information and pre-employment background checking process has not been established, although the utilization of such information is getting popular among the hiring professionals due to easy availability and cost friendliness. But the practices have given birth to evolving and severe controversies among the academicians, candidates and even practitioners. Particularly, the issue of mining social networking information by employers has led to legal and political controversies in some countries due to privacy and ethical concerns. However, it is apparent that such practice will continue to increase by the 
employers. Therefore, organizations are strongly recommended that they safeguard themselves by keeping consistency with the existing federal and state laws regarding this issue. In addition, organizations must formulate and implement a precise social media policy (SMP) and communicate with the job applicants from the beginning of the recruitment $\&$ selection process in order to avoid any unexpected outcomes.

\section{REFERENCES}

1. Baumhart, P. B.m 2015. Social media and the job market: How to reconcile applicant privacy with employer needs. University of Michigan Journal of Law Reform, 48(2), pp.502-533.

2. Berkelaar, B. and Bazzanell, P., 2014. Cybervetting, personenvironment fit and personnel selection: Employers' surveillance and sense making of job applicants' online information. Journal of Applied Communication Research, 42(4), pp.456-476.

3. Brandenburg, C., 2008. The newest way to screen job applicants: A social networker's nightmare. Federal Communications Law Journal, 60 (3), pp.597-626.

4. Brooks, C., 2016. Social screening: What hiring managers look for on social media. [pdf] Available at: <https://www.gcvf.org/wpcontent/uploads/2016/12/Social-Screening_-What-Hiring-ManagersLook-for-On-Social-Media.pdf> [Accessed o23 March, 2019].

5. Brown, V. R. and Vaughn, E. D., 2011. The writing on the (Facebook) wall: The use of social networking sites in hiring decisions. Journal of Business and Psychology, 26, pp.219-225.

6. Brutocao, S., 2012. Issue spotting: The multitude of ways social media impacts on employment law and litigation, The Advocate, 60, pp.8-10.

7. Boyd, D. N. and Ellison, N. B., 2007. Social network sites: Definition, history and scholarship. Journal of Computer Mediated Education, 13(1), pp.210-230.

8. Campion, M. A., Palmer, D. A. and Campion, J. E., 1997. A review of structure in the selection interview. Personnel Psychology, 50, pp.655-702.

9. Cooley, D. O. and Park-Yancy, R., 2016. Impact of traditional and internet/social media screening mechanisms on employers' perceptions of job applicants. The Journal of Social Media in Society, 5(3), pp.151-186.

10. Davison, H. K., Bing, M. N., Kluemper, D. H. and Roth, P. L., 2016. Social media as a personnel selection and hiring resources: Reservations and recommendations. In: R. N. Landers, G. B. Schmidet, R. N. and Landers, G.B. 2016. (Eds.), Social Media in Employee Selection and Recruitment: Theory, Practice and Current 
Challenges (pp.15-42). Cham, Switzerland: Springer International Publishing.

11. Elzweig, B. and Peeples, D. K.. 2009. Using social networking web sites in hiring and retention decisions. Advanced Management Journal, pp.27-35.

12. Egan, E., 2012. (Chief Privacy Officer), Protecting Your Passwords and Privacy. [Facebook] 15 March. Available at: <http://www.facebook.com/note.php?note_id=326598317390057.> [Accessed 15 March, 2019].

13. Gates, S., 2013. CISPA amendment banning employers from asking for Facebook passwords blocked. [online] Available at: $<$ https://www.huffpost.com/entry/cispa-amendment-facebookpasswords-blocked_n_3128507> [Accessed 25 February, 2019].

14. Gatewood, R. D., Feild, H. S. and Barrick, M., 2008. Human Resource Selection (6th ed.). Mason, OH: South-Western.

15. Ghoshray, S., 2013. The emerging reality of social media: Erosion of individual privacy through cyber-vetting and the law's inability to catch up. Journal of Marshall Review of Intellectual Property Law, 12, pp.551-562.

16. National Conference of State Legislatures, 2017. Access to social media usernames and passwords. [online] Available at: $<$ http://www.ncsl.org/research/telecommunications-and-informationtechnology/employer-access-to-social-media-passwords2013.aspx\#2016> [Accessed 17 March, 2019].

17. Gruzd, A., Jacobson, J. and Dubois, E., 2017. You're hired: Examining acceptance of social media screening of job applicants. Twenty-third Conference on Information Systems, Boston, May, 2017.

18. Harrison, J. and Budworth, M. H., 2015. Online presence could affect job seeker's hiring chances and salary. [online] Available at: $<$ https://news.yorku.ca/2015/07/30/online-presence-could-affect-jobseekers-hiring-chances-and-salary-york-u-study/> [Accessed 22 March, 2019].

19. Jobvite, 2014. Social recruiting survey. [pdf] Available at: $<$ https://www.jobvite.com/wpcontent/uploads/2014/10/Jobvite_SocialRecruiting_Survey2014.pdf> [Accessed 20 March, 2019].

20. Joyce, S., 2016. The basics of personal online reputation management. Career Planning \& Adult Development Journal, 32(2), pp.81-87.

21. Messiah, N., 2012. Survey: 37\% of your prospective employers are looking you up on Facebook. [online] Available at: <https://thenextweb.com/socialmedia/2012/04/18/survey-37-of-yourprospective-employers-are-looking-you-up-on-facebook/> [Accessed 1 March, 2019]. 
22. Ollington, N., Gibb, J., and Harcourt, M., 2013. Online social networks: An emergent recruiter tool for attracting and screening. Personnel Review, 42(3), pp.248-265.

23. Park-Yancy, R. and Cooley, D., 2015. Are you making the right impression? Preparing now for your real life after college. Wilmette, IL: Decabooks LLC.

24. Ramasastry, A., 2012. Can employers legally ask you for your Facebook password when you apply for a job? Why congress and the state should prohibit this practice. Verdict. [online] Available at: <https://verdict.justia.com/2012/03/27/can-employers-legally-askyou-for-your-facebook-password-when-you-apply-for-a-job> [Accessed 5 March, 2019].

25. Saylin, G. and Horrocks, T., 2013. The risks of pre-employment social media screening. SHRM. [online] Available at: $<$ https://www.shrm.org/resourcesandtools/hr-topics/talentacquisition/pages/preemployment-social-media-screening.aspx > [Accessed 27 February, 2019].

26. Segal, J. A., 2017. Legal trends social media use in hiring: Assessing the risks. HR Magazine. [online] Available at: <https://www.shrm.org/hr-today/news/hr-magazine/pages/0914social-media-hiring.aspx $>$ [Accessed 10 March, 2019].

27. Segal, J. A., 2014. The law and social media in hiring. HR Magazine, 59, pp.70-72.

28. Slovensky, R. and Ross, W. H., 2012. Should human resource managers use social media to screen job applicants? Managerial and legal issues in the USA. Info, 14(1), pp.55-69.

29. Stoughton, J. W., Thompson, L. F. and Meade, A. W., 2015. Examining applicant reactions to the use of social networking websites in pre-employment screening. Journal of Business and Psychology, 30(1), pp.73-88.

30. Suder, S., 2014. Pre-employment background checks on social networking sites-May your boss be watching. Masaryk University Journal of Law and Technology, 8(1), pp.123-136.

31. Tham, J. and Ahmed, N., 2011. The usage and implications of social media networking sites: A survey on college students. Journal of Interpersonal, Intercultural and Mass Communication, 2(1), pp.1-11.

32. Statista, 2017. Percentage of U.S. population who currently use any social media from 2008 to 2017. Statista. [online] Available at: $<$ https://www.statista.com/statistics/273476/percentage-of-uspopulation-with-a-social- network-profile/> [Accessed 1 April, 2019].

33. Van Iddekinge, C. H., Lanivich, S. E., Roth, P. L. and Junco, E., 2013. Social media for selection? Validity and adverse impact potential of a Facebook-based assessment. Journal of Management, 42(7), pp.1811-1835. 
34. Waring, R. L. and Buchanan, F. R., 2010. Social networking web sites: The legal and ethical aspects of pre-employment screening and employee surveillance. Journal of Human Resources Education, 4(2), pp.14-23.

35. Weathington, B. L. and Bechtel, A., 2012. Alternative sources of information and the selection decision-making processes. Journal of Behavior and Applied Management, 13 (2), pp.108-120.

36. Willey, L., White, B. J., Domagalski, T. and Ford, J. C., 2012. Candidate screening, information technology and the law: Social media considerations. Issues in Information Systems, 13(1), pp.300309.

37. Yarbrough, J. R., 2018. Is cybervetting ethical? An overview of legal and ethical issues. Journal of Ethical and Legal Issues, 11, pp.1-23

38. Zeidner, R., 2007. How deep can you probe? HR Magazine, 52(10), pp.57-60.

Received: 30 October, 2019

Accepted: 4 December, 2019 
